\title{
Current Trends in Adolescent Substance Use in Jamaica
}

\author{
U Atkinson ${ }^{1}$, WD Abel ${ }^{2}$, P Whitehorne-Smith ${ }^{2}$
}

\begin{abstract}
Objective: National secondary school-based drug surveys facilitate the identification and understanding of patterns of substance use among adolescents, associated risk and protective factors which exist and inform prevention and treatment interventions and policies which are appropriate for resource constrained settings. This paper analyses current trends as well as reviews trends from the last National School Survey conducted by the National Council on Drug Abuse in 2006.

Method: The study utilized a survey design that included a representative sample of secondary school students. Data were collected from 3365 students from 38 schools across the island. The study made specific reference to the prevalence of alcohol, tobacco cigarette, marijuana and inhalant use among secondary school students.

Results: The most widely used substances among the sample were alcohol, tobacco cigarettes, marijuana and solvents/inhalants. A large number of students (64\%) reported a lifetime prevalence of alcohol use. Alcohol use was also the highest for one-year (44\%) and one-month (33.6\%) use. While lifetime use of tobacco cigarette was higher than marijuana, one-year and one-month use of marijuana was higher than that of tobacco cigarette. There has been a slight increase in the age of initiation for alcohol, tobacco cigarette and marijuana use. There has also been a significant decrease (approximately 50\%) in lifetime, past year and past month prevalence of inhalant use since the 2006 secondary school survey.

Conclusions: Alcohol continues to be the substance most widely used by Jamaican adolescents, followed by tobacco, marijuana and inhalants. Though the average age of first use has slightly increased for all substances, prevalence remains a concern. As such, innovative school-based interventions are required to assist in reducing substance use among Jamaican adolescents.
\end{abstract}

Keywords: Adolescence, drug use, secondary school surveys

WIMJ Open 2015; 2 (1): 15

\section{INTRODUCTION}

The issue of drug use and misuse among Jamaica's adolescent population continues to be one of concern, especially as numerous bodies of research have pointed out that adolescence is the period of time in which most persons begin experimentation with substances of abuse (1-2).

Additionally, persons who begin a pattern of drug use during adolescence tend to continue using it well into their adult lives and are vulnerable to misusing and becoming dependent on drugs (2-4).

Drug or substance misuse is a term that has been coined to encompass the overall negative consequences associated with "problem" use, ranging along the spectrum of inappropriate use, abuse and aspects of dependence which are significant enough to warrant treatment (5).

Substance misuse has a wide range of psychological, developmental, social and economic consequences. Adoles-

From: ${ }^{1}$ National Council on Drug Abuse, 2-6 Melmac Ave, Kingston 5 and ${ }^{2}$ Department of Community Health and Psychiatry, Section of Psychiatry, The University of the West Indies, Kingston 7, Jamaica.

Correspondence: Mrs U Atkinson, National Council on Drug Abuse, 2-6 Melmac Ave, Kingston 5, Jamaica. E-mail: uatkinson@ncda.org.jm cents who begin using substances of abuse become susceptible to developing behavioural and psychological problems such as truancy, risky sexual practices, depression, impaired memory and poor academic performance. They also tend to be more involved than their non-using counterparts in criminal activity and accidents linked to intoxication $(1,6)$.

From an economic standpoint, dependency on alcohol, tobacco and other drugs (ATOD) can result in a heightened healthcare bill due to ATOD-related illnesses, loss of productivity in the workforce, cost of damages due to criminal activities, increasing law enforcement teams to combat crime, provision of housing and welfare for drug-dependent citizens and their families as well as the cost for detection, prevention, treatment, rehabilitation, research and educational programmes (4).

Considering the magnitude of these implications for national development, the National Council on Drug Abuse (NCDA), in collaboration with the Organization of American States/Inter-American Drug Abuse Control Commission (OAS/CICAD), periodically conducts National Secondary School Surveys. School-based drug surveys are important as they provide current and reliable information on drug use patterns. This article highlights findings from the most 
recent National Secondary School Survey regarding the main drug consumption trends and patterns.

\section{SUBJECTS AND METHODS}

This was a cross-sectional study which received ethical approval from the University Hospital of the West Indies/ University of the West Indies/Faculty of Medical Sciences Ethics Committee. The study utilized a survey design that included a representative sample of secondary school students in 38 schools across the island. Schools and students were randomly selected from a complete list of secondary schools (both public and private). Students were sampled from grades 8, 10, 11 and 12 .

The survey questionnaire was based on the InterAmerican Uniform Drug Use System (SIDUC) questionnaire. This is a standardized self-administered question-naire comprising 99 items which captured information related to sociodemographic characteristics, drug use patterns, psychosocial risk and protective factors for drug use and exposure to prevention and/or treatment programmes.

The study was endorsed by the Ministries of Health and Education. Letters were sent to selected schools, parents and students to gain permission for their participation in the survey. Informed consent forms and assent forms were delivered to the schools prior to the time of data collection. Early morning class periods were selected for data collection which occurred in a two-week period (October 7-18, 2013). Students whose parents declined and students who directly refused to participate in the study were accommodated in another class until data collection was undertaken.

\section{Data analysis}

Data were entered and cleaned by trained data entry clerks in a Microsoft Excel database specially designed by OAS/ CICAD. The data were then exported to the Statistical Package for the Social Sciences (SPSS) version 17, for the purpose of descriptive and inferential statistical analysis. The level of confidence utilized was $p \leq 0.05$.

\section{RESULTS}

Data were collected from 3365 students from 38 schools across the island. Most of the students who participated in the study were female $(57.3 \%)$ with a mean age of 14.97 (SD \pm $1.71)$ years and attended public schools $(97.9 \%)$ that were co-educational $(84.8 \%)$. Students were sampled from 12 parishes across the island (excluded parishes were Trelawny and Hanover). The parishes that represented the largest percentage were the Kingston and St Andrew area (KSA) with $21 \%$ of the sample, followed by St Catherine (19.2\%) and St James (12.5\%). Other parishes were sampled in smaller frequencies.

\section{Substance use}

The substances most widely used among the sample were alcohol, tobacco cigarettes, marijuana and solvents/inhalants.
Approximately $64 \%$ of students reported a lifetime prevalence of alcohol use. Alcohol also accounted for the highest percentages for one-year use (44\%) and one-month use $(23.6 \%)$. Lifetime use of tobacco cigarettes was more frequently reported than lifetime use of marijuana. However, one-year and one-month use of marijuana was higher than that of one-year and one-month use of tobacco cigarettes (Fig. 1).

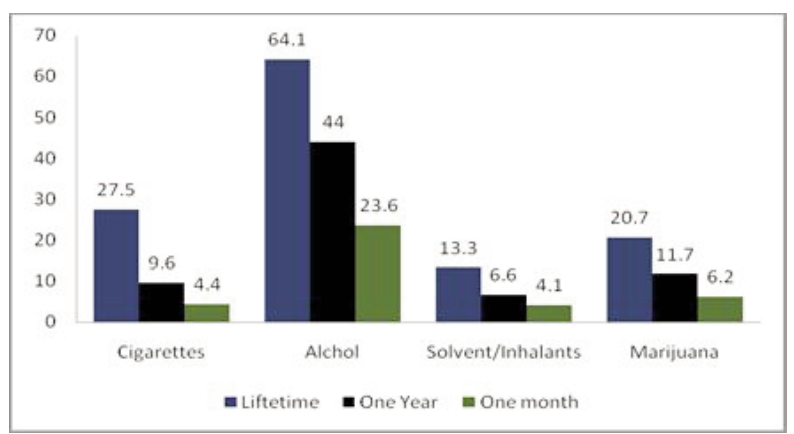

Fig. 1: Lifetime prevalence of main substances reportedly used by adolescents.

A comparative examination of the results from the 2006 National Secondary School survey (7) pinpoints slight changes in trends. While alcohol is the most commonly used substance across surveys, current findings show slight decreases in lifetime and past year prevalence; this was also true for marijuana. However, past month alcohol use has remained the same (Fig. 2).

Also, lifetime and past year prevalence of tobacco cigarette reflect slight increases, while past month prevalence has remained the same. There has been a significant decrease (approximately 50\%) in lifetime, past year and past month prevalence of inhalant use since 2006 (Fig. 2).

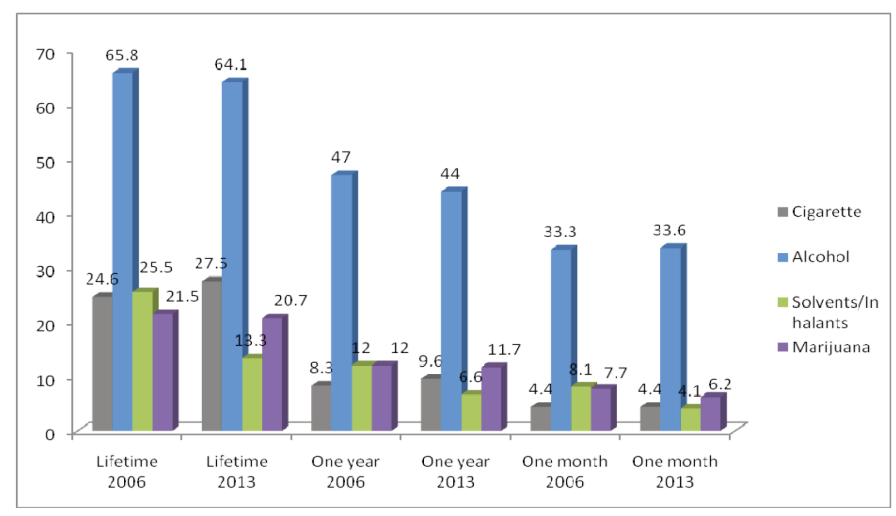

Fig. 2: 2006 and 2013 lifetime, one-year and one-month prevalence by substance.

Noteworthy, is the increase by approximately one year in the age of first use of the three main substances when compared to the 2006 survey findings (Table). Nonetheless, alcohol use reflected the youngest age of initiation, followed by tobacco cigarettes and then marijuana. 
Table: $\quad$ Age of first use by substance

\begin{tabular}{lcc}
\hline Substance & \multicolumn{2}{c}{$\begin{array}{c}\text { Age of first use (years) } \\
\text { 2006 }\end{array}$} \\
& $\mathbf{2 0 1 3}$ \\
\hline Tobacco cigarettes & 11.8 & 12.7 \\
Alcohol & 11.7 & 12.6 \\
Marijuana & 12.9 & 13.3 \\
\hline
\end{tabular}

\section{DISCUSSION}

This study consisted of a representative sample of secondary school students across the island. Findings showed that the primary drugs used by these students were alcohol, tobacco cigarettes, marijuana and solvents/inhalants. The data indicate that alcohol has been the substance that is most widely used by Jamaican adolescents with a lifetime prevalence of over $60 \%$. The cultural acceptance of this substance has been attributed to Jamaica and the wider Caribbean's historical experience as producers of sugar cane and rum (8).

However, there was a slight decrease in the reported rate of lifetime and one-year alcohol use and parallel onemonth prevalence for this substance. While this study did not capture information to conclusively explain substance use, several health promotion campaigns have been put in place in the recent past to curb the drinking habits of youngsters. These campaigns, some of which were sponsored by liquor companies, sought to discourage underage drinking and promote responsible drinking practices. These may account for the slight shift in trends.

An interesting finding is that while lifetime use of tobacco cigarettes was higher than marijuana use, past year and one-month use of marijuana was marginally higher than that of one-year and past month tobacco cigarette use. This finding is consistent with those reported in the NCDA 2006 Secondary School Survey (7). However, there is variability as it relates to the prevalence of use of these substances.

Additionally, this trend followed through for solvent/ inhalant use and marijuana use which show decreases in the use of these substances over lifetime, one year and one month. This trend did not follow for tobacco cigarette use which showed a marginal increase from the 2006 school survey results despite the recent passing of legislation that banned smoking in public places.

There was a marginal increase in age of first use when compared to that reported in the 2006 school survey (7) for alcohol, tobacco cigarettes, marijuana and solvents/inhalants use. This may be attributed to island-wide school based prevention programmes such as Resistance Education Against Drugs which aim to delay the onset of substance use among young people. Also, there was an overall decrease in substance use across all grade levels for alcohol, tobacco cigarettes and marijuana, except in the case of tobacco cigarette and cannabis use among grade 11 students, where there were marginal increases in substance use.
Moreover, lifetime, one-year and one-month use of alcohol was higher among those students 17 years or older, whereas lifetime, one-year and one-month use of marijuana and tobacco cigarettes was higher among students between the ages of 15 and 16 years. Lifetime use of solvents/inhalants was higher among the 15-16-year age groups, while one-year and one-month use was more common among the 17 years or older age group.

It is accepted that consistent surveillance of trends in the prevalence, patterns and associated risk and protective factors informs a nation's response to substance use among its youth. Tracking this information also helps to determine whether drug prevention and treatment interventions among the in-school youth population have impacted the patterns of use of licit and illicit substances.

The sustained prevalence of alcohol, tobacco and marijuana use among the secondary school population over the two survey periods implies that prevention efforts require scaling-up at multiple levels. Multi-pronged strategies involving the youth, education, health and national security sectors should be evaluated and adjusted to effectively address the risk and protective factors for drug use among adolescents. Additionally, these surveys do not include unattached out-of-school youth who may be more at risk for substance misuse and require targeted interventions. It is recommended that a similar surveillance system be undertaken to monitor trends among unattached youth.

\section{ACKNOWLEDGEMENTS}

This study was funded and supported by the Inter-American Drug Abuse Commission (CICAD). This research project would not have been possible without their support as well as approval of the Ministries of Health and Education and all the facilitators and students who agreed to participate in this study.

\section{REFERENCES}

1. Kandel DB, Yamaguchi K, Chen K. Stages of progression in drug involvement from adolescence to adulthood: further evidence for the gateway theory. J Stud Alcohol 1992; 53: 447-57.

2. Kilpatrick DG, Acierno R, Saunders B, Resnick HS, Best CL, Schnurr PP. Risk factors for adolescent substance abuse and dependence: data from a national sample. J Consult Clin Psychol 2000; 68: 19-30.

3. Chambers RA, Taylor JR, Potenza M. Developmental neurocircuitry of motivation in adolescence: a critical period of addiction vulnerability. Am J Psychiatry 2003; 160: 1041-52.

4. Douglas K. Patterns of substance use and abuse among post primary students. Kingston: Planning Institute of Jamaica; 2000.

5. Department of Health (England) and the devolved administrations. Drug misuse and dependence: UK guidelines on clinical management. London: Department of Health (England), the Scottish Government, Welsh Assembly Government and Northern Ireland Executive; 2007. Available from: http://www.nta.nhs.uk/uploads/clinical_guidelines_ 2007.pdf

6. Deas D, Thomas S. Comorbid psychiatric factors contributing to adolescent alcohol and other drug use. Alcohol Res Health 2002; 26: 116-21.

7. National Council on Drug Abuse. National Secondary School Survey 2006. Washington, DC: Organisation of American States/InterAmerican Drug Abuse Control Commission (OAS/CICAD); 2006. 
8. Organisation of American States/Inter-American Drug Abuse Control Commission. Exploring the relationship between drugs and crime: a comparative analysis of survey data from prisoners in four Caribbean countries. Washington, DC: OAS/CICAD; 2012. Available from: http://www.cicad.oas.org/oid/pubs/CaribbeanPrisons2012.pdf
Submitted 13 Oct 2014

Accepted 27 Oct 2014

Published 16 Mar 2015

Online: http://www.mona.uwi.edu/wimjopen/article/1628

(C) Atkinson et al 2015

This is an open access article made freely available under Creative Commons Attribution 4.0 International (CC BY 4.0). Users are free to share, copy and adapt this work as long as the copyright holder (author) is appropriately and correctly credited. See http://creativecommons.org/ licences/by/4.0/deed.en_us for more information. 